\title{
Intercultural encounters as hospitality. An interview with Richard Kearney
}

\section{Breffni O'Rourke'}

Originally from Cork, Ireland, Richard Kearney is Charles B. Seelig Professor in Philosophy at Boston College. Among his many books, three titles in particular are representative of the themes discussed in this interview: Hosting the stranger (Continuum, 2011, co-edited with James Taylor); On stories (Routledge, 2002); and Strangers, gods, and monsters: interpreting otherness (Routledge, 2003). What will be of most immediate interest to readers of the Journal of Virtual Exchange is the Guestbook Project, which Kearney founded in 2009. Guestbook is an online experiment in conflict resolution through sharing stories across borders.

The interview took place on the 10th of March 2018 in Dublin, where Professor Kearney was speaking at a conference and launching his new book with Sheila Gallagher, Twinsome Minds: An act of double remembrance (Cork University Press, 2017). This is an edited transcript of the conversation.

\section{Keywords: intercultural communication; conflict resolution; personal stories; hospitality; continental philosophy.}

BOR $^{2}$ What is the Guestbook Project? What does it do?

$\mathbf{R K}^{3} \quad$ The Guestbook Project is an attempt to bring young people together, in divided communities politically divided, socially divided, religiously divided, culturally divided - and to invite and

\footnotetext{
1. Trinity College Dublin, Dublin, Ireland; orourkeb@tcd.ie

Breffni O'Rourke (Trinity College Dublin) is Associate Professor in Applied Linguistics and Manager of Language Learning Technologies and Resources, and is a member of UNICollaboration's Executive Board. His research focusses on online communication by language learners. He teaches Pedagogical Grammar of English, Discourse Analysis, Technology, Language, and Communication, and First Language Acquisition.

2. Breffni O'Rourke, interviewer

3. Richard Kearney, interviewee
}

How to cite this article: O’Rourke, B. (2018). Intercultural encounters as hospitality. An interview with Richard Kearney. Journal of Virtual Exchange, 1, 25-39. Research-publishing.net. https://doi.org/10.14705/rpnet.2018.jve.2 
encourage them to tell their own story, listen to that of their adversary on the opposite side, and then to come together and construct a third story.

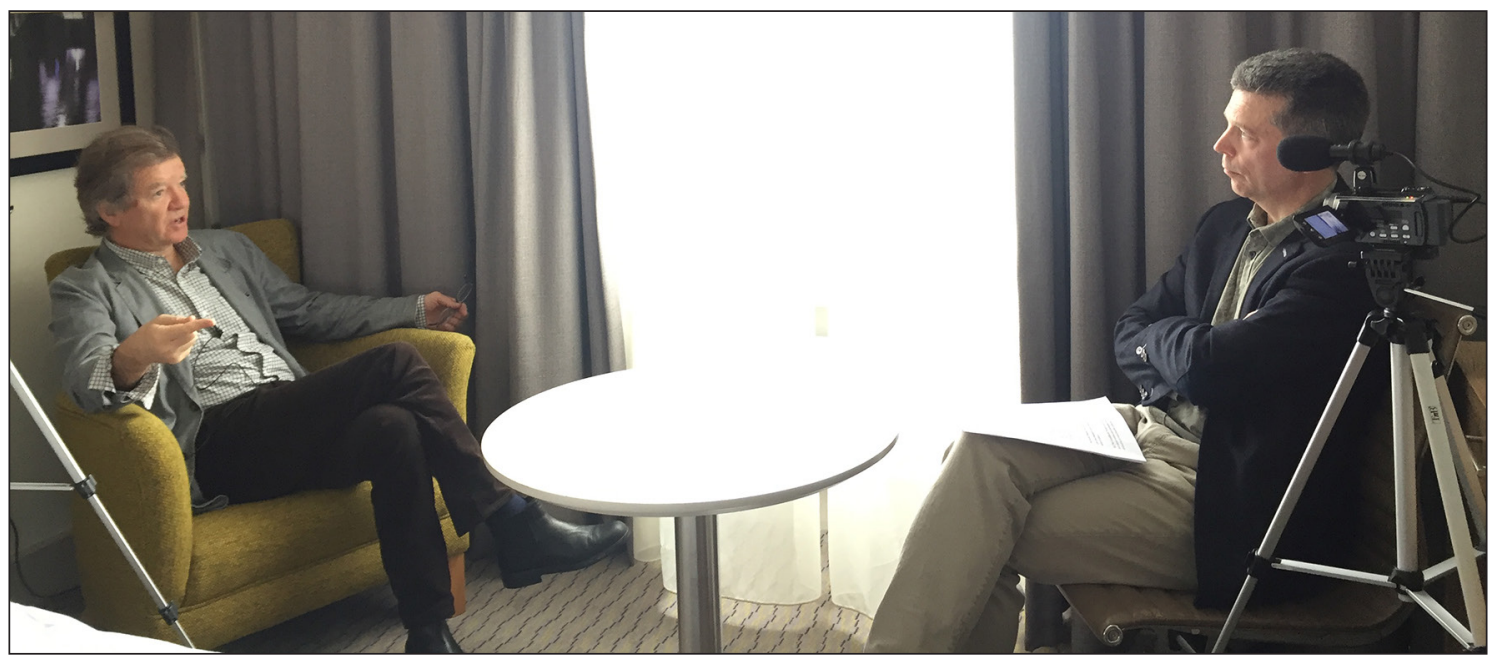

[Photo credit: Anne Bernard Kearney]

This is usually done audio-visually and is recorded on video - very often now on iPhone - and submitted to our website, which is a kind of classroom without walls for hospitality and peace. Then we select and post these submissions under three categories: Documentary, which can involve a group of young people from different sides; a section called Exchanging Stories - Changing History, which is a one-to-one from the two different sides. We've had Palestinian and Israeli, we've had Croat and Serb, we've had Catholic and Protestant from Derry, we've had Black and White from South Africa, and so on. Then the third is Storybites, where an individual simply talks into an iPhone for one to two minutes, recording a story of transformation when they encountered a stranger. Sometimes that stranger is included in camera, but not necessarily.

That actually has proved to be the most accessible and probably most democratic of all the approaches in that it doesn't involve setting up cameras, it doesn't involve lighting problems or sound problems. We do a little bit of editing sometimes when the videos are submitted.

And then, once a year our aim is to host an international festival. We're doing Zagreb this summer, then Boston, and then hopefully Cape Town where we have a partnership with the Institute for Justice and Reconciliation, which is the offshoot of the Truth and Reconciliation 
Tribunal in South Africa; we're working quite closely with them and with other partnerships throughout the world. We run Guestbook on a very small budget; it’s mainly voluntary, and it's non-profit.

BOR How do you reach the people who contribute their stories and their videos?

RK It's mainly been by contagion: the website's up there, it's on YouTube, and word carries, image carries; and then through the partnerships, especially the Center for Digital Storytelling [now called StoryCenter], Global Unites, Narrative 4, and so on. The more word gets out, the more submissions start coming in.

BOR What's your hope for it? That this will be inspirational to the viewers, or that it will encourage reflection in the contributors, or something else?

RK I would say both. Let me give a few examples. One of the earliest ones we did was in Northern Ireland. We partnered with the Nerve Centre in Derry who invited two young girls from a Protestant and a Catholic school in Derry. They made a video together where they told their respective stories using archive materials and visuals and then got together and exchanged uniforms and went into each other's schools.

Very simple, their own idea, which we then posted on the website. It went viral, in its own little British-Irish way anyway: I think there were something like fifty thousand hits in the first week, and then it was picked up by the British and Irish papers - the Guardian ran a big piece on it - and they ended up as sort of peace ambassadors going to other schools, creating a mobile and virtual 'classroom without walls' as we like to call it.

This also happened in the commemoration of the Armenian Genocide. An Armenian and a Turk got together, two students. The Turk had never met an Armenian, the Armenian had never met a Turk. They just sat down at a table and talked about their respective stories, in terms of how they first came to hear of the Armenian Genocide, and the extraordinary thing was that the Armenian student said that the word 'Turk' was the worst word in the Armenian language, though her parents and grandparents had never spoken about the genocide. When they left Armenia they had never spoken about it - it was just too traumatic. Likewise, the worst word for the Turkish student growing up in Istanbul was 'Armenian', but he didn't know why. It was because he'd never heard of the genocide either; it was suppressed for other reasons in Turkey. Recognising that the worst four-letter word in their respective languages was naming someone because of an event that had never been spoken 
about transgenerationally: that was a moment of real breakthrough - a strange interlinguistic epiphany - and together they went on to form a student youth movement for the commemoration of the genocide. So you know, a little moment can become something bigger, and that's how it works.

BOR And Guestbook provides that opportunity.

RK That's right. Our next phase is to build a platform with a sufficient number of Storybites, Exchanging Stories and Documentaries, the three brands, and to offer a very simple downloadable 'Peace Pedagogy' package, where peace groups and schoolrooms - primary, secondary, tertiary - can access it, and adapt it in their own particular way to their own particular circumstances.

BOR Drawing on the materials that have been contributed as various Storybites, etc.?

RK They would be seen as samples, yes. In a classroom situation some might make a documentary, others an Exchanging Stories piece, others a Storybite, and if they choose to submit it to us, then at the end of the year at our international festival we would invite some of them to show their work. That's a way of actually bringing them together physically as well as, obviously, virtually, online.

BOR What's particularly interesting about this is, first of all, the name: 'Guestbook'. In virtual exchange, when we bring groups together from different countries or communities, we think of them as meeting in something like a 'third place', kind of a neutral space; or that there's a kind of conduit of communication between them. This virtual space where they're meeting, whether it's through video conferencing or through online forums, is neither there nor here, it's a shared space; but you talk in terms of 'guests' and 'hosts' and 'hospitality', and that's a recurring theme in your work. At first glance that seems asymmetrical - you're the host and I'm the guest - so can you tell me how that feeds into the model, or how it inspires it, and why? What's the power of that metaphor of hospitality?

RK Well, what first struck me about the term 'hospitality' was that it has the same root as 'hostility', and that the word for 'enemy' and 'friend', 'host' and 'guest', in most Indo-European languages, is actually the same: xenos in Greek; hostis, hospes in Latin; both of those derivations of the root can mean either 'enemy' or 'friend', either 'host' or 'guest'. We even have, say in French, table d'hôte and être hôte; it means guest and it means host. So there's a common root to hospitality and hostility. Jacques Derrida coined the term hostipitality, because it can go either way... 
BOR ...because you've got this duality...

RK Exactly. The exchange of stories may create a certain liberty of space to remake history, reinvent history, and open up new possibilities of history that have never been fulfilled in the past. Our inheritance is a set of promissory notes: not just what has happened, but what also has not happened, or not yet happened - but which could still exist. So it's about exploring that opening-up of new possibilities through this exchange of histories into stories, of hosts into guests, and vice versa. It takes away the power premise of "I'm the host with power, and you're the guest at my mercy”.

BOR Because it is in fact reciprocal.

RK Yes, reciprocal and reversible. As is, in a fragile and contingent sense, the process of hospitality and hostility. Hospitality, like love, or peace, is a devalued word - we have the "hospitality industry" - but behind that word that has in some senses lost its original meaning, there's this very powerful metaphor of the reversibility and transversability of host and guest.

BOR There is also a kind of ethical value attached to the notion of hospitality, which isn't there in the simple notion of communication. There are duties attaching to the host and to the guest.

RK That's right; and it's a loaded word, it's a charged word. It's a beautiful word, and it's got a history in all of the Indo-European languages. But it's so relevant for what's happening in terms of emigration in our own times. In the United States of course it's huge: the Mexican border, the whole question of who is and who is not an American. But, over here, also who is and who is not an Irish citizen, a British citizen, a European citizen, the whole question of sharing of sovereignties, and obviously the massive immigration issues, issuing from Iraq and Syria and so on. So it's very, very relevant from the point of view of the whole refugee problem.

BOR The other thing is stories, of course. The major content of the Guestbook Project, and I guess the major output, are these stories. To contrast it a little with virtual exchange: virtual exchange is very open, and there's no reason why personal stories mightn't enter into it, but in my experience it very often operates on a more generalising or abstract level. If an exchange has an explicit intercultural focus, then when the students are telling personal stories, the point isn't primarily the personal story; it's what that tells us about the culture. But what for you is the power of the individual story? And I emphasise story rather than experience, because once you tell a story you're structuring it, it's not just a recounting of fact. 
RK Well going back to Aristotle, since I'm a philosopher for my living, he made an important distinction in his Poetics between history and story. History is chronicle - telling something as it happened, one thing after another. He uses the phrase meta - one thing after another. Whereas story - mythos-mimesis - means redescribing what happened through a mythos, a plot, putting a figure onto what is otherwise a mere sequence of events, a serial flow of moments one after the other. The poetic plot can turn time around, begin in the middle, in medias res, as most epic stories did, and then go back or go forward and so on. So it's a freedom of imagination over events, transforming one after (meta) another into one thing because of (dia) another. In that way, story is free to brush time against the grain, to reconfigure history into a meaningful form or pattern - turning accidents into essences, particulars into universals (to use Aristotle's own terms).

Coming back to your question of culture, we may say accordingly that every national culture is an imagined community. That doesn't mean it's unreal. In fact, Aristotle would say it's even more real, it's even more true, because the truth of something is accessed more through story than history. History is an accumulation of facts - we need that forensic, empirical evidence but story is what gives essential meaning (eidos) to the data. It is what makes the given into a gift, so to speak. That is what Paul Ricoeur, in Time and Narrative, calls the 'threefold mimesis of time': the prefiguring, configuring, and refiguring of our otherwise random experience. If we do it in art, we can do it in life too. Moving from action to text back to action. Lifenarrative-life. The triadic dialectic of narrative imagination.

BOR Stories are also where meaning becomes contestable.

RK Exactly, and that's democracy. The exchange of stories as a healthy and necessary contestation. It becomes a drama. A creative 'conflict of interpretations' (Ricoeur), that aims towards great consensus without ever presuming to unite or totalise the different narrative perspectives into one. The detour through narrative imagination reminds us that we have the freedom to reimagine ourselves. We find ourselves within a plot called history - we are born into an inheritance of facts and figures - but we can redescribe that plot, while always having due regard, needless to say, for the past as what actually happened. But telling it as it actually happened, history, needs to be supplemented and complemented by story, which is telling it as if it happened like this or that; as it could have happened, should have happened, might have happened. Story can thus retrieve and reignite some of the unfulfilled or unexplored 'possibilities' of the past. Storytelling shows us that that beside actual history lies possible history, and it is possibility that gives a future to the past. 
BOR In the case of the Guestbook contributions, the Storybites and the other formats offer us personal stories. I saw a very nice one about a Rwandan-Congolese couple for example. They talk about how they met, and the relationships with the families. That is very much a personal story: they're not telling the story of Rwanda or of the Congo or of their people...

RK No-but personal stories like this are symptomatic of those cultural stories, collective stories, which they're embedded in. The forbidden nature of their liaison is only because Rwandans have this hostile view towards the Congolese and vice versa. Or ditto for nationalists and unionists in Derry or divided people in countless other places. The culture is carried in the bones. But, you know, by telling their personal stories, the transgenerational traumas and silences and prejudices and wounds that they carry within them are brought to bear in a much more personal and dramatic way - they are brought into the open, translated into words and images that can be 'worked through' (as Freud and the trauma therapists would say). In being narrated and exchanged, incurable wounds become healable scars. They are illumined and felt. Without concrete incarnate stories, you're left with ideological abstractions, the grand narratives of Official History. We need micro-stories to counterbalance macro-histories.

BOR So it's left to the viewer to think through questions like "What does this all mean for my situation? For me as a nationalist or unionist in Derry? For me as a Croat or Serb in the Balkans?” - or whatever else your national allegiance might be.

RK And it should be translatable and transferrable in that way. That's why I talk about communication in that sense as contagion - in the positive sense of contagious transmission; an example or model that can be taken from Northern Ireland and applied to South Africa or vice versa. These communities, these dialogues taking place in very specific cultures, and personal stories, when they're shared on the internet, can actually create a space and time for saying "We're not the only ones who are screwed by history; this has happened over there and look what they've been able to do" in however basic or small a way. These possible transmissions are working on the micro-narrative level.

In fact, the book we launched here in Dublin last night, Twinsome minds: an act of double remembrance, was a multimedia attempt to tell the micro-narratives of 1916, both in the Battle of the Somme, the Irish who died there - five thousand in a single day - and then the five hundred who died in the streets of Dublin in Easter week of $1916^{4}$. The multimedia

4. A reference to the Easter Rising against British rule in Ireland. 
performance, upon which the book is based, attempts to tell the war stories of siblings - from the same homes, families, same parishes, communities - who found themselves on opposite sides: untold or repressed stories that didn't fit in to the official histories of binary opposition, British versus Irish.

By working with the micro-stories, the macro can actually be revisited in new ways. The story opens up history and shows it not to be a mausoleum of dead congealed facts but a laboratory of meanings that can constantly be revisited and reimagined. Because the past is never past. It's always being re-lived, again and again. The child is father of the man. We carry not only our own personal past with us, as Freud realised, but also our collective history, conscious and unconscious.

Our unconscious wounds and desires are often strangers within us. It's important to realise that, deep down, we're strangers to ourselves - as well as to each other. There's a philosophical and an ethical premise to the Guestbook Project: that strangers are not just those out there, refugees and immigrants arriving at borders - but also alienated and unacknowledged parts of our own selves. The strangers within us return to us as uncanny doubles and ghosts - as Heidegger $^{5}$ and Kristeva ${ }^{6}$ remind us in their analysis of die Unheimlichkeit [the uncanny] ${ }^{7}$ and if we can understand how so many of our fears and scapegoats result from our own unconscious projections, we're more likely to be more tolerant and open to the strangers in others. Otherwise the tendency is to say "Well, I know exactly who I am, who we are; we're not strangers to ourselves, we're all united in a single, indivisible, sovereign nation or community; the others are the strangers, out there". That creates a binary that the Guestbook is trying to challenge and transcend.

Take the example of the guest and the host in translation. Hospitality is a process of translation where the host language receives the guest language. If you're translating text from Greek into English, for example, something happens to English and to Greek. There's a mutual revision and re-invention of the resources of both languages. But we'll only be really open to this reciprocal linguistic 'othering' if we acknowledge the stranger and the strangeness within ourselves, and within our own mother tongue. The mother tongue is never totally our own, there's always something of the Other, the Trojan Horse within the citadel of the same. The alien within the origin. The multiple within the one. There is no

5. Heidegger, M. (1962). Being and time. Translated by J. Macquarrie \& E. Robinson. Blackwell.

6. Kristeva, J. (1991). Strangers to ourselves. Translated by L. S. Roudiez. Columbia University Press.

7. Freud, S. (2003). The uncanny. Translated by D. McLintock \& H. Haughton. Penguin. 
pure dialect of the tribe. We all speak after Babel. There's always some gap between you and your words, somewhere.

BOR Something like that idea of strangeness, and becoming strange to yourself, lies behind one popular model of virtual exchange, called Cultura, designed by Gilberte Furstenberg at MIT. The sequence of activities is based on comparing cultures, for example through word associations: what do you associate with police, what do you associate with religion. Each group looks at the associations that the other side - an American group, for example - had with police, but then they also reflect on what associations they as, say, Spanish people have with police, and ask themselves where that comes from. Because the enemy of openness in a way is not recognising that you're not the centre of the universe, and that you are as strange to others as they are to you.

You've brought up in a couple of places the idea of risk. Virtual exchange is risky in all sorts of mundane ways. Anybody who does it will tell you the technology isn’t always reliable, it can be organisationally risky, it can be pedagogically risky: projects may not have the outcomes that you hoped for. It's also risky socially and interpersonally, for these people who talk about themselves and their cultures. Even where it isn't a conflict situation like the ones you work with, there's always a risk of loss of face, even in fairly mundane ways. Can you say something about that idea of risk in meeting the Other? The risk that's involved in hospitality?

RK Well, even in our ordinary language we say "I'll risk an interpretation, I'll risk a phrase". Even to speak to another person is to risk translating your intentions into a language that can be understood or misunderstood, and as soon as it's out there it's subject to multiple interpretations. There's always a risk in exposing yourself, in betraying your feelings by putting them into words - yes, you literally betray yourself. As Lady Macbeth says to Macbeth, "Your face, my Thane, is as a book where men / May read strange matters" - and that's even before Macbeth puts his thoughts into words. There's always risk of betraying yourself by communicating.

But the first act of civilisation was a handshake, which was already an act of hospitality by putting out an open hand rather than reaching for the sword. Abraham and Sarah did it with the three strangers at Mamre ${ }^{9}$, and the basic story is that in welcoming the hostis, and in risking your home, by inviting these three strangers out of the desert to enter your

8. Act 1, Scene 5

9. Genesis $18: 2$ 
home as foreigners, as strangers, to share your food, you could lose everything; or you could bring about a new civilisation: the Abrahamic ethic of hospitality to 'widows, orphans, and strangers', and, for the Abrahamic religions, to the divine. Insofar as there is a god in Judaism that can be named or seen, it is the stranger, and Christianity also starts with the arrival of a stranger, and a young Nazarene woman who says "yes” to that annunciation.

You know, this goes right down through Western and other civilisations; it's that wager of hospitality, that the enemy, or the seeming enemy, the stranger, may be befriended, may turn from enmity to amity. That's always a risk and a wager, and I think hospitality loses its edge, its drama, its radical import and urgency if it loses that audacity.

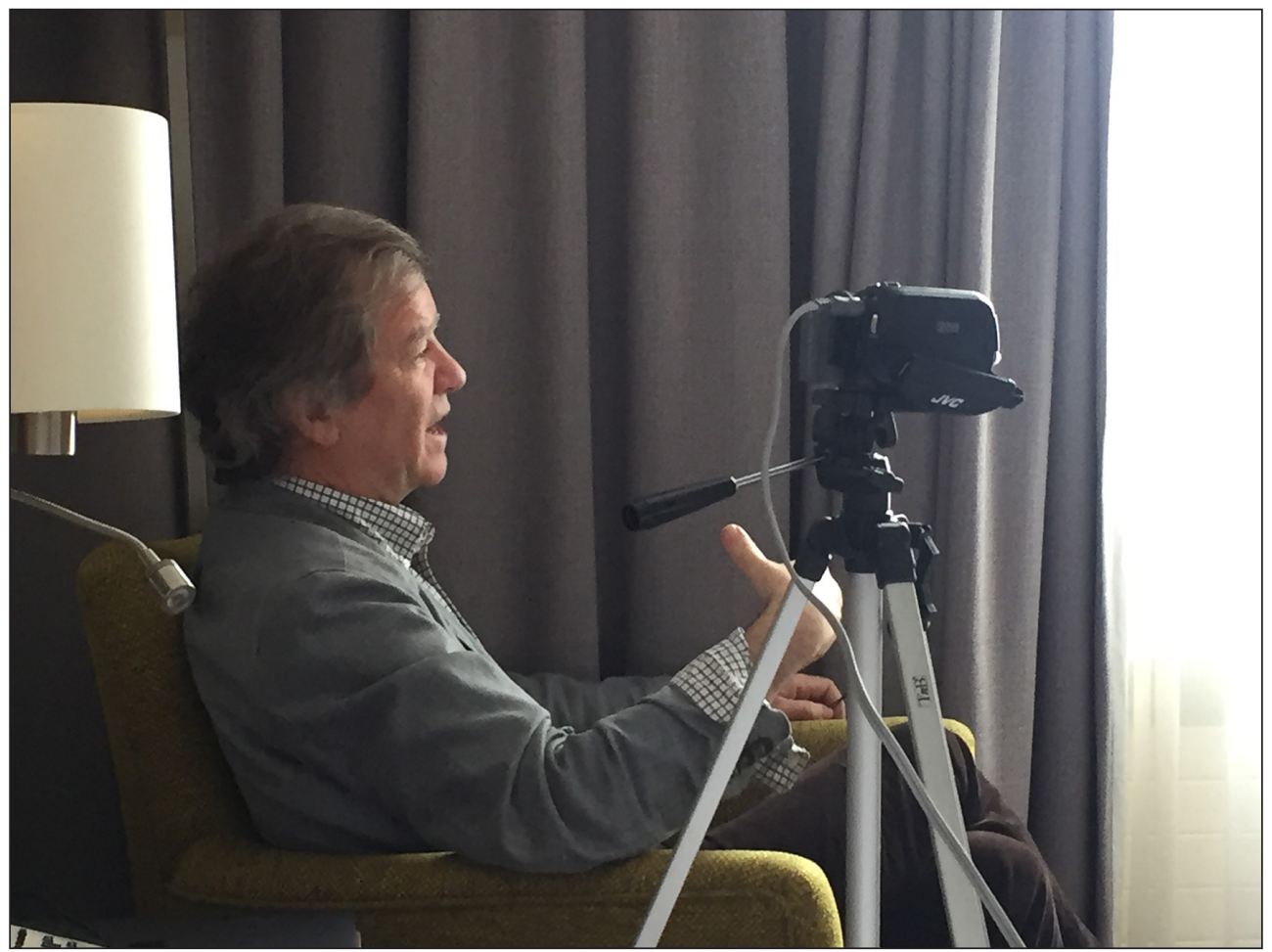

[Photo credit: Anne Bernard Kearney]

Hospitality is never achieved once and for all, it can risk becoming hostility the next moment. In fact, even in the Abrahamic story in Genesis, two episodes later ${ }^{10}$ there's the appalling 
betrayal of hospitality when Lot, who is Abraham's brother-in-law, is surrounded by the citizens of Sodom, and he's faced with this terrible situation of having to sacrifice his gueststrangers to their violence. So it's not that hosting the stranger is something achieved forever. It is realised for a moment by Abraham and Sarah only for Lot to be faced with this terrible dilemma. It's an on-going trial. L'épreuve de l'étranger, as Antoine Berman put it.

BOR So it's a situation that has to be constantly monitored and negotiated and can't be taken for granted.

RK Yes. Like the European Union [EU], which we're discussing at this moment. It was a moment of hospitality in the 1950's when Adenauer got together with Guy Mollet and then Jean Monnet, saying "We've had too much hostility, Europe has to pool sovereignties and work together". Now, with Brexit and the rise of a new nationalist populism in Italy and elsewhere, we have to renegotiate what trans-national and trans-regional hospitality means between peoples. If we just say it's a fait accompli, then the EU dies; of boredom, of bureaucracy, of smugness, but sometimes a realisation of danger and threat to the European vision reminds us of the inaugural risk and audacity of the project. It's a real summons to rethink what inter-cultural hospitality really means, in terms of living with twenty-seven other nations.

BOR Work with conflict and conflict resolution has been a strand of your career; you were involved in peace initiatives in Northern Ireland even long before the Good Friday Agreement ${ }^{11}$, and now you're involved in Guestbook. Has your study in philosophy led you to this interest, or is it a coincidental convergence?

RK I think sometimes there is sort of felicitous chiming of my experience of hospitality in real life and my readings about the philosophy of hospitality with my mentors in Paris, where I did my doctoral degree: Paul Ricoeur, for whom the whole notion of linguistic hospitality was huge what could be called a 'hermeneutics of translation' - saw Europe as an exchange of wounded memories healing through narrative exchange. That was very important for me, the ethic of narrative pooling and reversibility.

BOR And was that partly the personal experience of being in France, and of being in some sense a guest in France as an Irish person?

11. The wide-ranging centrepiece agreement of the Northern Ireland peace process, achieved in 1998 following many years of multilateral talks. 
RK Well, it's interesting that you say that, although I haven't thought of that before; but it was true I was a 'guest of the nation' in France: free education for my entire doctoral degree, where I was lucky enough to work with Paul Ricoeur, Emmanuel Levinas, and Jacques Derrida in the late 1970's - three masters of the philosophy of hospitality who have all written books on the subject. That obviously was an important influence.

I was asked by someone at one of our Guestbook seminars in 2009; "Why did you get interested in all this? Had it anything to do with your own personal experience?” I thought about it and I said, well, maybe it is related to the fact that I grew up in Ireland at a time when there was a war going on in the north of the island. I recounted one particular experience which I realised was quite fundamental to my thinking. It happened when I was moderating a conversation between two groups: IRA [Irish Republican Army] prisoners on the nationalist/Catholic/ republican side and UDA [Ulster Defence Association] prisoners on the unionist side. One of the republicans told the story of how he had nearly been shot. He had been taken out of his bed, blindfolded, handcuffed, brought to a barn in the boot of a car, tied up, and was about to be shot. He asked his assassin, could he smoke a last cigarette? The assassin said yes; and as he was smoking the cigarette he told the story of how he himself had joined the IRA and why he had shot people. He described what had happened to his grandfather, being tortured by the B-Specials ${ }^{12}$, and then how his father had been taken out and kneecapped; how his mother had had a breakdown and become an alcoholic and ended up on the street, and how his brother had been tortured... He went through a litany of appalling brutalities, and told how he had become so full of anger and hatred that he went out and shot his enemies. There was a silence after he'd finished the cigarette and he waited - five minutes, ten minutes, twenty minutes - for the gun to go off, but no gun went off. When finally he untied himself and turned around - there was nobody there. The barn was empty. He walked home.

He finished telling that story, and another person stood up at the back of the room and said "I was the loyalist paramilitary who was about to shoot you, but when I heard your story, I realised it was also my story, and I couldn't shoot you". That did affect me - an exchange of narratives where one person discovered himself in the enemy, through this exchange of stories in pretty dramatic circumstances. The fact that the incident occurred in the northern part of my country and that so many people since have been working under very difficult circumstances towards some kind of peace agreement that eventually came about in 1998, gives some kind of hope. It seemed impossible that John Hume would ever shake hands with the devil, or that the Queen of England and Ian Paisley would ever talk to republican

12. A controversial police force in Northern Ireland, 1920-1969, drawn chiefly from the unionist/Protestant community 
nationalists like Martin McGuinness and Gerry Adams, but these gestures have occurred. They occurred with Mandela and De Klerk. Sadat and Begin. They can happen.

BOR And in every case with tremendous political risk.

RK Huge, and death, assassination; that's the risk too. There's another story that I like to tell, going back to old Anglo-Norman-Irish struggles ${ }^{13}$ where the Fitzgeralds and the Ormonds were at war with each other. At one point the Fitzgeralds surrounded the Ormonds in Dublin Cathedral and Gearóid Mór Fitzgerald said: "Cut a hole in the door and I will take off my armour and put my arm through. You can cut it off or you can shake my hand. If the first, the war continues; if the second, the war ends”. They shook hands and the war ended. That's where the common colloquial phrase to "chance your arm" comes from. For me, such little stories (petits récits, as Lyotard called them, often occluded and ignored by official history), carry seeds of hope that the impossible can become possible. So that's the wager behind the Guestbook.

BOR I'm interested in online discourse of all sorts, and it seems to me that, at least in certain corners of the internet, people are very, very far from reaching that point of risking something and making themselves vulnerable and saying "let's shake hands" because there's a step before that, which is just to engage with somebody, in the sense of listening to them, genuinely hearing what they have to say, trying to find out whether you want to change their minds, or whether maybe you need to revisit your own views. Instead, a culture has grown up of discourse as a blood-sport. A whole vocabulary has grown up around put-downs - defeating somebody, conquering somebody in discourse: there are terms like zingers, throwing shade, owning, burn...

RK Are these phrases particular to online conversations?

BOR I'm sure you'll find them in oral conversations as well, but people behave differently online. The social psychology of online behaviour is very interesting, and not perhaps as simple as one might think...

RK Well, it's surely about defence mechanisms - the safety of the touch screen where, ironically, one cannot be touched. It is one way. One has a certain vicarious and voyeuristic invulnerability in certain war or sex gaming. Of course such online conversations can also offer fragile people

13. The hostilities, following the Anglo-Norman invasion of the late 12th century, between the invaders and the indigenous Gaelic chieftains. 
a certain security where the normal defence reactions can be overcome and a certain safe space for free conversation opened up.

BOR If you read the comment sections in extreme right-wing media, for example, it's about insult, about conquest, about putting people in their place. If a liberal strays into a conservative website, to stay with that example, it's perceived as an assault or an encroachment, and they're told to “get out of here - we recognise you, you don't belong here”. Even on the other side, a liberal who strays into a forum like that typically isn't there with any realistic intention to change minds. They're not playing the game of changing minds.

Linguists and applied linguists are familiar with Grice, the ordinary-language philosopher. One of his notions of communication is that the foundation of communication is cooperation: that there's an accepted purpose or direction of any given talk-exchange. In a lot of online discourse, it seems to me, especially in these polarised times, the accepted purpose or direction is conquest, victory, triumph, putting the interlocutor down. Do you see any prospect for ventures like the Guestbook or virtual exchange to change the mindset with which people approach that kind of discourse?

RK Well, it's the old phrase, “the hair of the dog that bit you”. If there's a lot of toxic violence going on in this anonymous, faceless, excarnate discourse online, get in there and change it. Go to the source of it and use anonymity for the good.

It is an ethical dilemma. Go to hostility and convert it into hospitality. I think there is something about telling the good stories of people caught in a trap of repetition, compulsive repetition, where sometimes going into the virtual world liberates them from the noxious cycles and gives them a laboratory of imaginary possibilities to explore other options and then return to their life again.

I think the important thing is that, as Paul Ricoeur put it, you go from 1) action (your lived experience), to 2) text (let's say the virtual text, textuality, the Web), back to 3) action. Ricoeur calls it a hermeneutic narrative circle of prefiguration-configuration-refiguration. That passage through the otherness of the text, where, yes, we enter an alien, anonymous world where we are othered, where we are no longer ourselves and can assume personas (whether you're reading a novel or you're online), this can have real liberating potential. As long as you know you came from a real world and you return to the real world where you have responsibilities to real others. So you go from flesh to virtuality to flesh; carnation to excarnation to re-carnation. I think if you keep that circuit, that hermeneutic circle always 
in mind, there's less likelihood of getting lost in the realm of the purely anonymous. So the virtual online world has, in such circumstances, the capacity for an important emancipatory function. Though it always carries the other side of the screen - the lure of dissimulation and manipulation: a masking function open to the perversions of power, bullying, and violence that you describe.

BOR You're based in the United States, and you started the Guestbook Project in a very different time, around the time Barack Obama was elected. Now there's a very different figure occupying the American presidency; nationalism seems to be on the rise in Europe, and authoritarianism. The US seems to be extremely polarised ideologically, between conservatives and liberals. Does that make you despondent or pessimistic in light of the kind of thing that you're trying to achieve?

RK Well, you know, hospitality does not exist without, alas, the constant shadow of hostility. It's all the more reason, when faced with Brexit and the rise of extreme neo-nationalism in countries like Hungary, Croatia, Poland and, of course, in Trump's America, to get down and work on this. I'm very encouraged by, for example, the recent reaction to the gun massacres in the Florida school ${ }^{14}$. Youths are speaking again; there's also Black Lives Matter on campuses and increasing crowd protests in US cities not seen since the civil rights marches. As Hölderlin said, where the danger grows, there also grows the promise of change ${ }^{15}$. It's a huge challenge, but I don't give up hope. We're in dark times, but there are still glimmers.

BOR Thank you very much for your time.

14. Marjory Stoneman Douglas High School in Parkland, Florida, 14 February 2018.

15. Wo aber Gefahr ist, wächst / Das Rettende auch (Patmos, 1813). 
Published by Research-publishing.net, a not-for-profit association Voillans, France, info@research-publishing.net

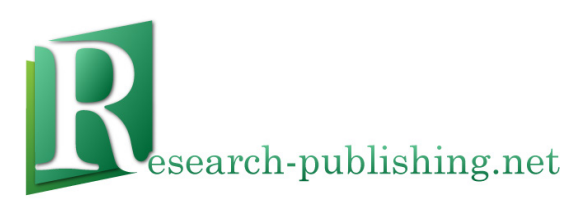

Journal of Virtual Exchange (JVE) is an online, open-access, peer-reviewed journal aimed at practitioners and researchers in the field known variously as virtual exchange, telecollaboration, or online intercultural exchange. It is the official journal of UniCollaboration (https://www.UniCollaboration.org/), the international academic organisation dedicated to supporting and promoting telecollaboration and virtual exchange in higher-level education.

Disclaimer. Research-publishing.net does not take any responsibility for the content of the pages written by the authors of this article. The authors have recognised that the work described was not published before, or that it was not under consideration for publication elsewhere. While the information in this article is believed to be true and accurate on the date of its going to press, neither UniCollaboration nor Research-publishing.net can accept any legal responsibility for any errors or omissions. Additionally, the publisher makes no warranty, expressed or implied, with respect to the material contained herein. While Research-publishing.net is committed to publishing works of integrity, the words are the authors' alone.

Trademark notice. Product or corporate names may be trademarks or registered trademarks, and are used only for identification and explanation without intent to infringe.

Copyrighted material. Every effort has been made by the editorial team to trace copyright holders and to obtain their permission for the use of copyrighted material in this article. In the event of errors or omissions, please notify the publisher of any corrections that will need to be incorporated in future editions of this article.

Typeset by Research-publishing.net

Noto fonts are open source. All Noto fonts are published under the SIL Open Font License, Version 1.1. Noto is a trademark of Google Inc. (https://www.google.com/get/noto/).

ISSN: in process (online only) 